\title{
UN FRAGMENTO DE PINTURA MURAL EN CACAXTLA, PALENQUE Y EL POPOL VUH
}

Marta Foncerrada de Molina

Voy a referirme en estas líneas al descubrimiento (1982) de un fragmento de pintura mural localizado en la zona suroeste de Cacaxtla, cerca del llamado Palacio (ver plano fig. 1) encontrado por una reducida cala que se hizo aproximadamente $2 \mathrm{~m}$, bajo el piso que niveló la cima de la montaña (Santana y Quintanilla, INAH, s. f.).

Por el tema y el estilo de la representación pictórica, este hallazgo confirma la importancia de la vertiente de influencia maya en la configuración del muralismo en Cacaxtla. Respecto a ello debe considerarse como importante argumento la filiación olmeca xicalanca de los fundadores de esta ciudad del Epiclásico, los que procedían de la Chontalpa tabasqueña y por lo tanto estuvieron relacionados geográfica y culturalmente con los mayas del área del Usumacinta. El argumento se refuerza con la reflexión sobre el carácter cosmopolita de Teotihuacan durante el auge de dicha ciudad, lo que presupone el asentamiento de mercaderes olmeca xicalancas y mayas y la posibilidad de asumir su éxodo parcial hacia el suroeste de Tlaxcala cuando sobrevino el colapso de la Metrópoli (Foncerrada de Molina, 1978a, 1980).

El fragmento de mural que me interesa analizar corresponde por estratigrafía a una etapa constructiva más temprana que la de los taludes de la batalla del Edificio B sub en el límite norte de la Plaza Norte. La cala en sí muestra dos fases constructivas, ya que el mural fue cubierto por un piso o relleno y por un muro transversal.

La parte despejada por los arqueólogos permite apreciar la sección de un mural más extenso cuyo estilo o iconografía desconocemos. El motivo visible se reduce a la siguiente descripción: planta de maíz conteniendo pequeñas cabezas humanas en lugar de frutos. El coniunto tiene $90 \mathrm{~cm}$ de altura y cada cabeza mide aproximadamente $15 \mathrm{~cm}$. Su apariencia es la siguiente: es una planta coloreada de azul con tallo y hojas cuya configuración estilizada corresponde a la de una planta de maíz pintada sobre un fondo rojo. No se aprecia el arranque del tallo por el piso - relleno que cubrió el mural en una etapa constructiva posterior. Se trata, por lo tanto, de un diseño incompleto, cortado también en su extremo izquierdo por un muro transversal. El motivo, a pesar de sus reducidas di- 
mensiones, está exquisitamente pintado; se aprecia el elegante movimiento divergente de dos tipos de hojas, unas cortas y redondeadas que salen del carrizo y otras delgadas y finas que, prolongándolas en ondulante movimiento, cuelgan hacia abajo. Una sutil línea amarilla pasa por el centro de cada hoja. Doble línea de contorno acentúa la pureza del diseño y marca en dos tonos de azul, más claro el de afuera, el reborde que configura el trazo vegetal.

En los espacios alternos que dejan la encontrada disposición de las hojas cortas, aparecen dispuestas pequeñas cabezas humanas de claro perfil maya. En el centro, tres de ellas son claramente visibles; a nivel del piso, asoma el perfil de una más, y otra parece rematar el tallo. Las centrales aparecen asentadas en las hojas cortas con el mentón incrustado contra el tronco común, en elegante ritmo alterno y divergente. La planta que, originalmente, debió tener más ramificaciones deja ver, ligeramente a la derecha, por encima de la delgada hoja que cae en movimiento elíptico, una flor azul, como un botón cuyo contorno esférico se ensancha a partir de un corto vástago, también azul y cuya superficie circular está partida en su base por una doble línea ondulante.

Los rostros son rostros mayas, claramente discernibles por sus rasgos: acentuada deformación craneana que alarga la cabeza en forma de pera o aguacate y rostro de larga nariz aquilina, boca entreabierta, carnoso labio inferior, mentón ovalado y ojos almendrados. Son cabezas con vida porque las pupilas están claramente señaladas con un punto negro. El pelo, teñido de rojo y con los mechones finamente delineados en negro, cae hasta el mentón cubriendo la oreja y se recorta en la frente a manera de fleco. El rostro es amarillo (aparentemente decorado, con delgadas líneas negras o rojas); este tono y su particular disposición en la planta puede interpretarse como el diseño antropomorfo de un elote (fig. 2).

El tono azul que colorea la planta y el rojo que le sirve de fondo, alejados de la percepción natural que de ellos tendríamos en la realidad, le imprimen al conjunto iconográfico cualidades sobrenaturales enfatizadas por la inesperada inserción de cabecitas humanas, las que la convierten en planta sagrada.

Dicha representación da lugar a una interesante asociación iconográfica con un motivo manejado de manera similar en los relieves del Tablero de la Cruz Foliada en Palenque (672 d.C.) (fig. 3).

En este caso se trata de dos cabezas humanas realistas que descansan en los brazos laterales de la enjoyada planta, y de una tercera en la es. quina inferior derecha, la que reposa entre las hojas de maíz que envuelven a un caracol del que emerge un diminuto dios narigudo, conjunto que 
le sirve de pedestal a la erguida figura de Pacal, gobernante de Palenque, quien con la sagrada planta cruciforme de por medio contempla a su sucesor, Chan Bahlum. Se trata de la representación de un ritual de ascensión al poder por parte de este último personaje. Lo envuelve una simbología de fecundidad y regeneración de la tierra en la que las cabecitas juegan tal papel. El hecho de que aparezcan decapitadas las remite a un rito sacrificial propiciatorio (Foncerrada de Molina, 1976) relacionado con la abundancia de la naturaleza. Desde otro punto de vista, tales cabezas son símbolos visuales que hacen referencia a los mitos de creación del hombre según aparecen narrados en el Popol Vuh, fuente literaria que a pesar de la distancia geográfica y temporal que la separa de Palenque, parece haber recogido en lengua quiché, en la temprana época colonial, tradiciones universales de la cultura maya, que pueden remontarse muchos siglos atrás. De acuerdo con esta fuente, las cabezas humanas están relacionadas con tres eventos simbólicamente recogidos en esta manifestación plástica de Palenque. Uno es la creación del hombre con masa de maíz, sustancia que los dioses formadores encuentran adecuada para crear seres que los reconozcan, reverencien y propicien. Otro es el sacrificio de los progenitores Hunahpu e Ixbalanqué por los señores de Xibalba, los de la región de la oscuridad y la muerte, quienes los decapitan y cuelgan sus cabezas en las ramas de un árbol. El tercer acontecimiento es la fecundidad de una de estas cabezas cuya saliva fertiliza a la doncella Ixquic, quien concibe a dos hijos, los gemelos heroicos, también de nombre Hunahpu e Ixbalanqué que habrían de enfrentarse con éxito y en numerosos incidentes con el maligno poderío de los señores de Xibalba.

Cito a continuación los pasajes del Popol $V u h$ que se refieren a lo arriba anotado.

"He aquí, pues, como se principió a tratar de la formación de la gente, buscando también la carne que entraría a formarla... Formaron sus carnes del producto de las mazorcas amarillas y blancas... Éstos fueron nuestros primeros padres, cuatro gentes fueron las gentes cuyas carnes formaron sólo con aquellos elementos" (Villacorta y F. Rodas, Séptima Tradición, 1927, p. 299). Éstos son los hombres de maíz de los que habría de descender el género humano.

Respecto al sacrificio de los progenitores Hunahpu e Ixbalenqué por los señores del Xibalba, quienes los decapitan, dice así el texto:

vayan a colocar sus cabezas en las ramas de un árbol que está sembrado en medio del camino... y fueron a dejar las cabezas entre las ramas del árbol, y entonces el árbol fructificó. .. gran importancia adquirió en sus corazones aquel árbol, a consecuencia de lo que había acontecido... 
entonces los de Xibalba se reunieron y dijeron: que nadie venga a coger de sus frutos y que ninguno se coloque bajo este árbol (Ibid, p. 233).

El árbol del que penden calaveras aparece en el mito como generador de vida cuando cuenta lo que le ocurrió a la doncella Ixquic al acercarse al árbol prohibido y hablar con las calaveras ahí colgadas:

En seguida fue ella sola y llegó al árbol... entonces halló una de las calaveras que estaba entre las ramas del árbol: ¿Qué es lo que deseas?... ¿Nos deseas? le preguntaron: Los deseo, contestó entonces la doncella. Está bien: extiende el extremo de uno de tus brazos para ver la mano dijeron las calaveras. Bien, dijo,la doncella y extendió los ex. tremos de sus brazos delante de las calaveras. Entonces las calaveras le dejaron caer saliva en las manos a la doncella...

Retornó la doncella a su casa después de haber oído aquello y apercibídose de lo que sería de ella. Solamente a causa de la saliva concibió seres vivos en su vientre y, éstos, pues, serían Hunahpu e Ixbalanque. (Ibid, p. 255).

Es posible asumir que la representación de cabezas humanas en el Tablero de la Cruz Foliada de Palenque reflejen simbólicamente lo narrado por el Popol Vuh. Éste es un problema aún no resuelto por los mayistas. Lo que me interesa consignar en estas reflexiones es la analogía iconográfica entre el motivo palencano descrito y la planta de maíz con cabecitas humanas de Cacaxtla. El diseño no corresponde al inventario plástico del Altiplano Central, por lo que queda abierta la posibilidad de considerarlo como una aportación palencana al ecléctico corpus iconográfico del muralismo en Cacaxtla.

Otro dato importante que proporciona esta cala es la existencia de otro mural un poco más tardío pintado en la pared de enfrente a la que he descrito, a $1.50 \mathrm{~m}$. de distancia de ésta y del que se aprecia lo siguiente: sobre un zoclo rojo que se desplanta del piso que cubrió parte del mural de la planta de maíz aparece la sección de una banda acuática segmentada en triángulos por franjas ondulantes amarillas, entre las que se asientan pequeños diseños ovoides. La banda le sirve de base a una alargada franja de apretadas plumas azules, la que sugiere ser la del cuerpo emplumado de una serpiente de la que desconocemos sus extremos (fig. 4). E1 cuadro central parece haberse dejado vacío. Sin embargo, vestigios de plumas en uno de los extremos superiores permite suponer que, como en el mural del Hombre-Pájaro del Pórtico del Edificio A, el cuerpo emplumado fue el de una serpiente erguida. El conjunto banda acuática-serpiente emplumada resulta un interesante antecedente, casi un experimento con los motivos que en este caso no aparecen asociados con la figura 

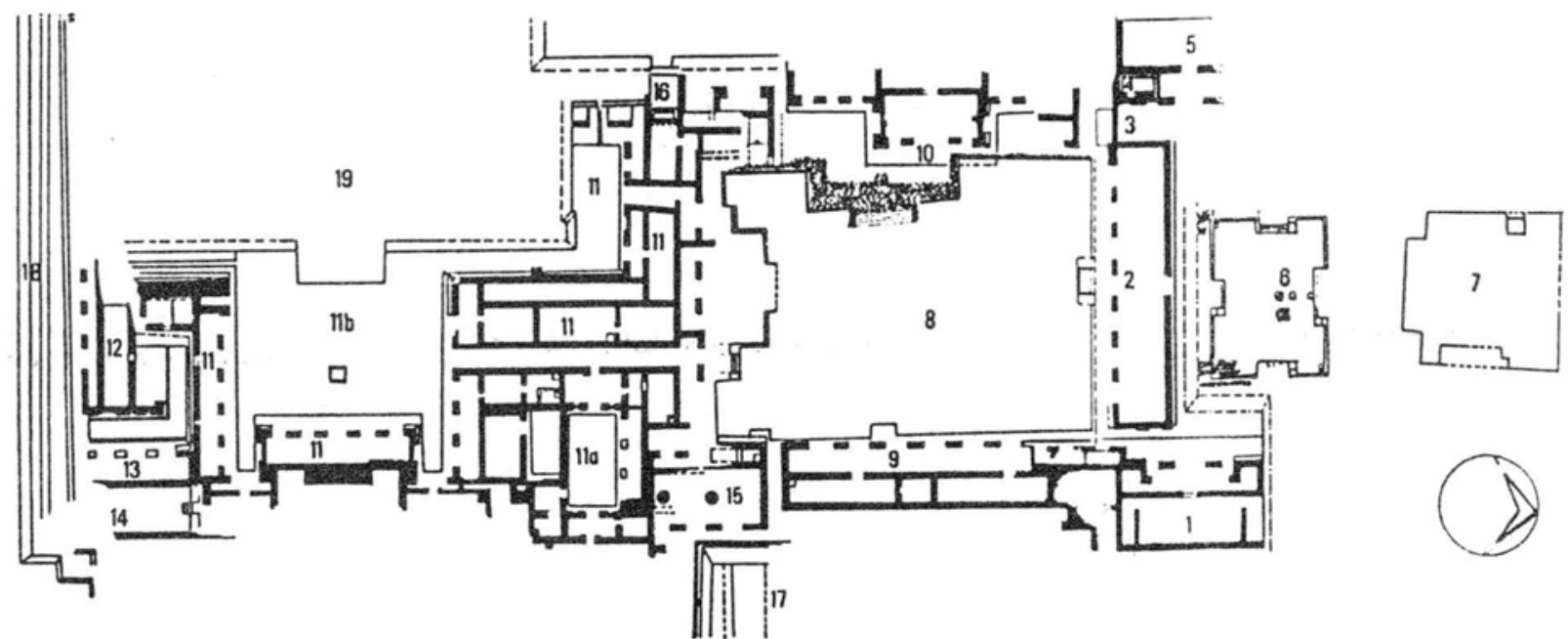

1. Edificio $A$ o de las Pinturas

2. Edificio $B$

3. Pasillo de los Tableros

4. Las "Conejeras"

5. Edificio $C$

6. Patio Hundido
7. Monticulo $Y$

8, Plaza Norte

9. Edificio $D$

10. Edificio $E$

11. El Palacio

11a. Patio de los Rombos 11b. Patio de los Altares

11c. Pórtico A

12. Edificio $F$

13. Pórtico $F$

14. Cuarto de la Escalera

15. Edificio de las Columnas
16. La Celosia

17. Taludes del Este

18. Taludes del Sur

19. Conjunto 2

Plano de la nomenclatura utilizada para las distintas estructuras excavadas en lo alto del Gran Basamento.

Figura 1. Plano de Cacaxtla.

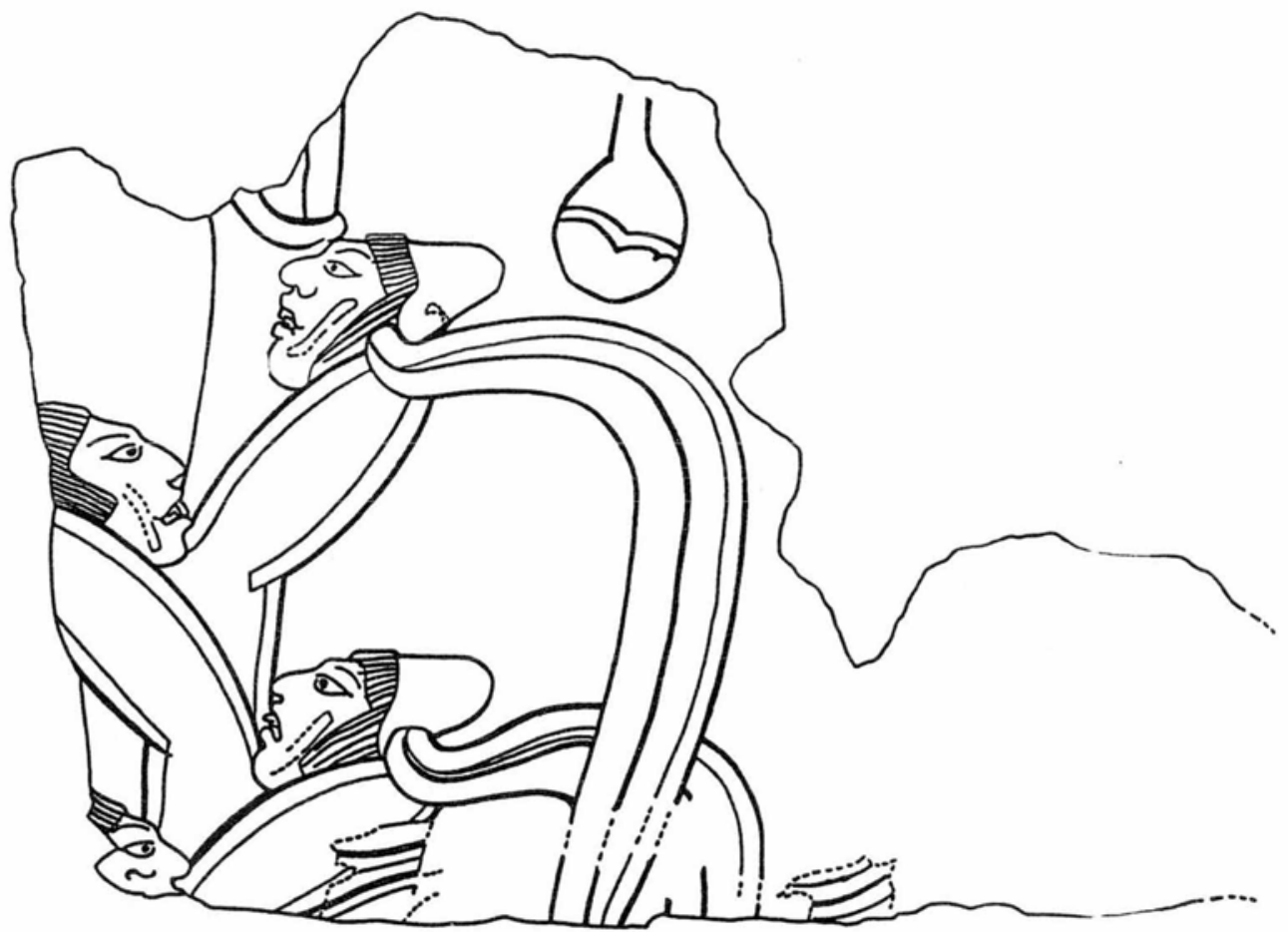

Figura 2. Cacaxtla. Fragmento de mural. Planta de maíz con cabecitas humanas (dibujo de Carlos Ontiveros). 


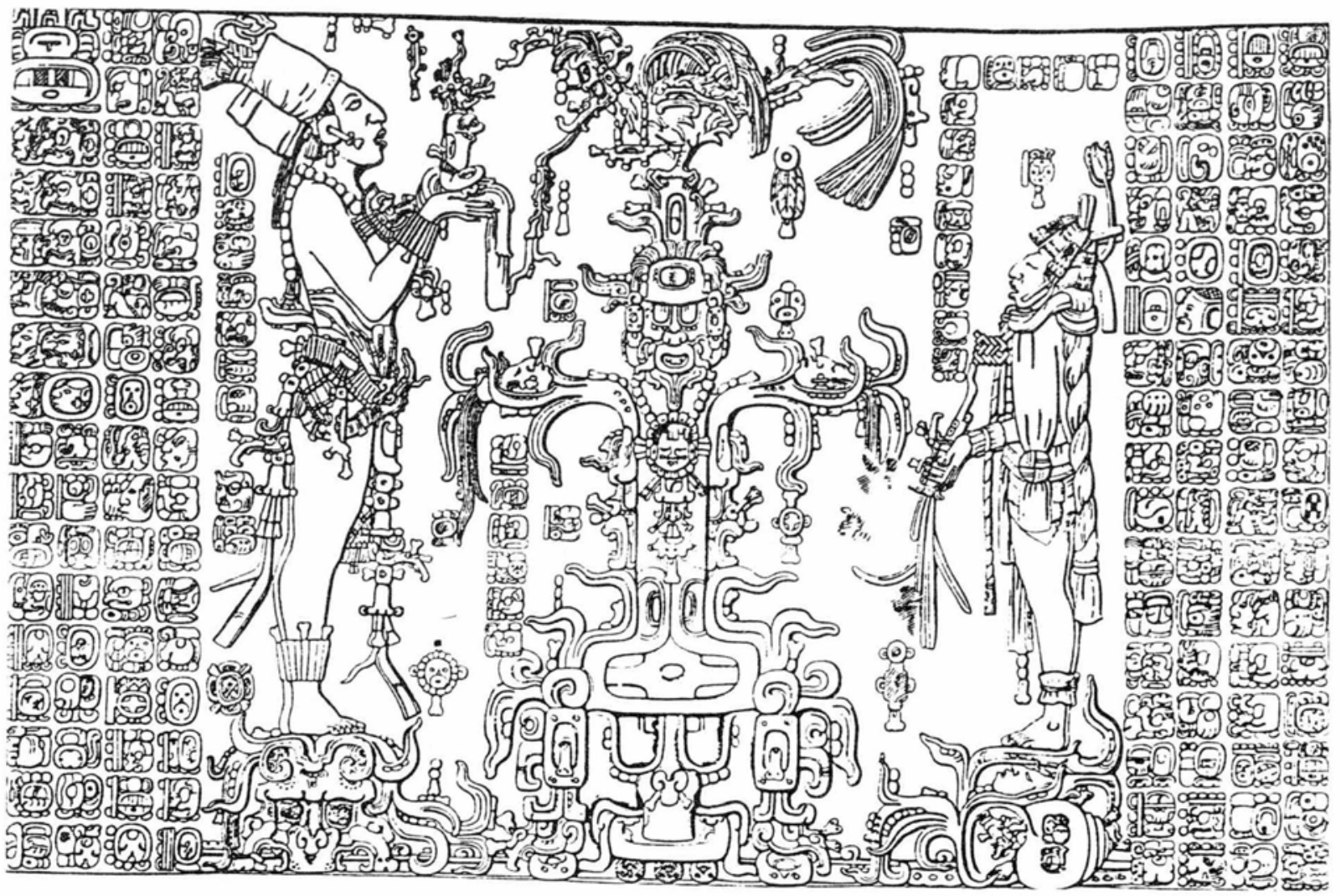

Figura 3. Palenque. Templo de la Cruz Foliada. Tablero santuario (Maudslay, IV, 1974). 


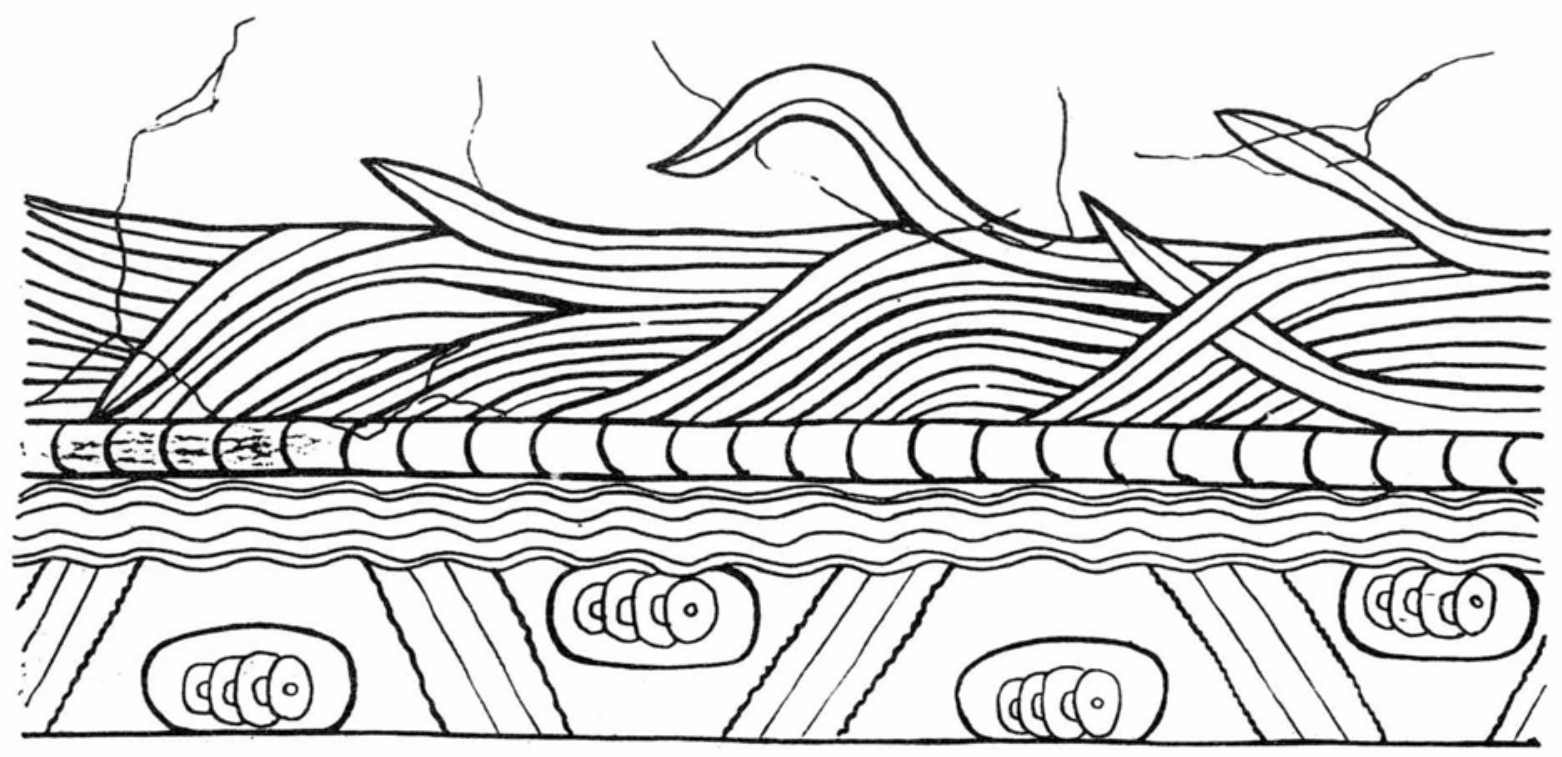

FCO. VilliASAN̄OR \&

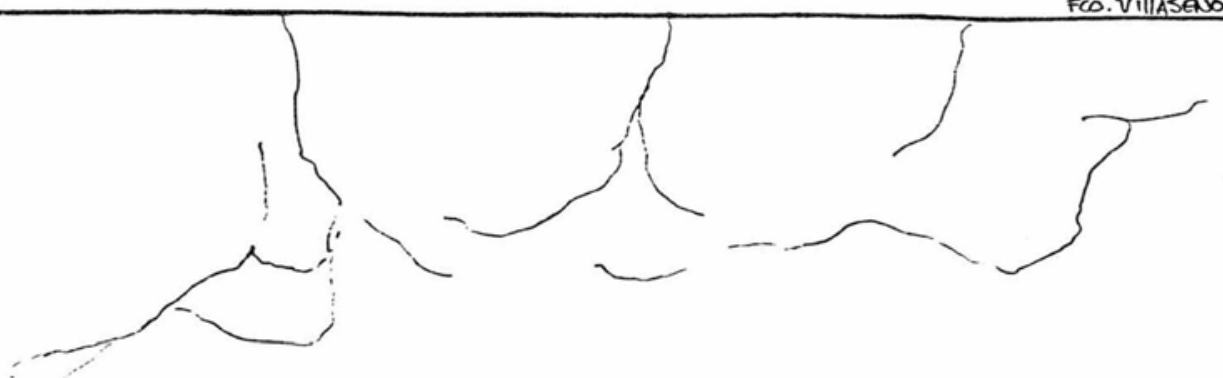

Figura 4. Cacaxtla. Fragmento de mural. Banda acuática y cuerpo emplumado (dibujo de Francisco Villaseñor). 


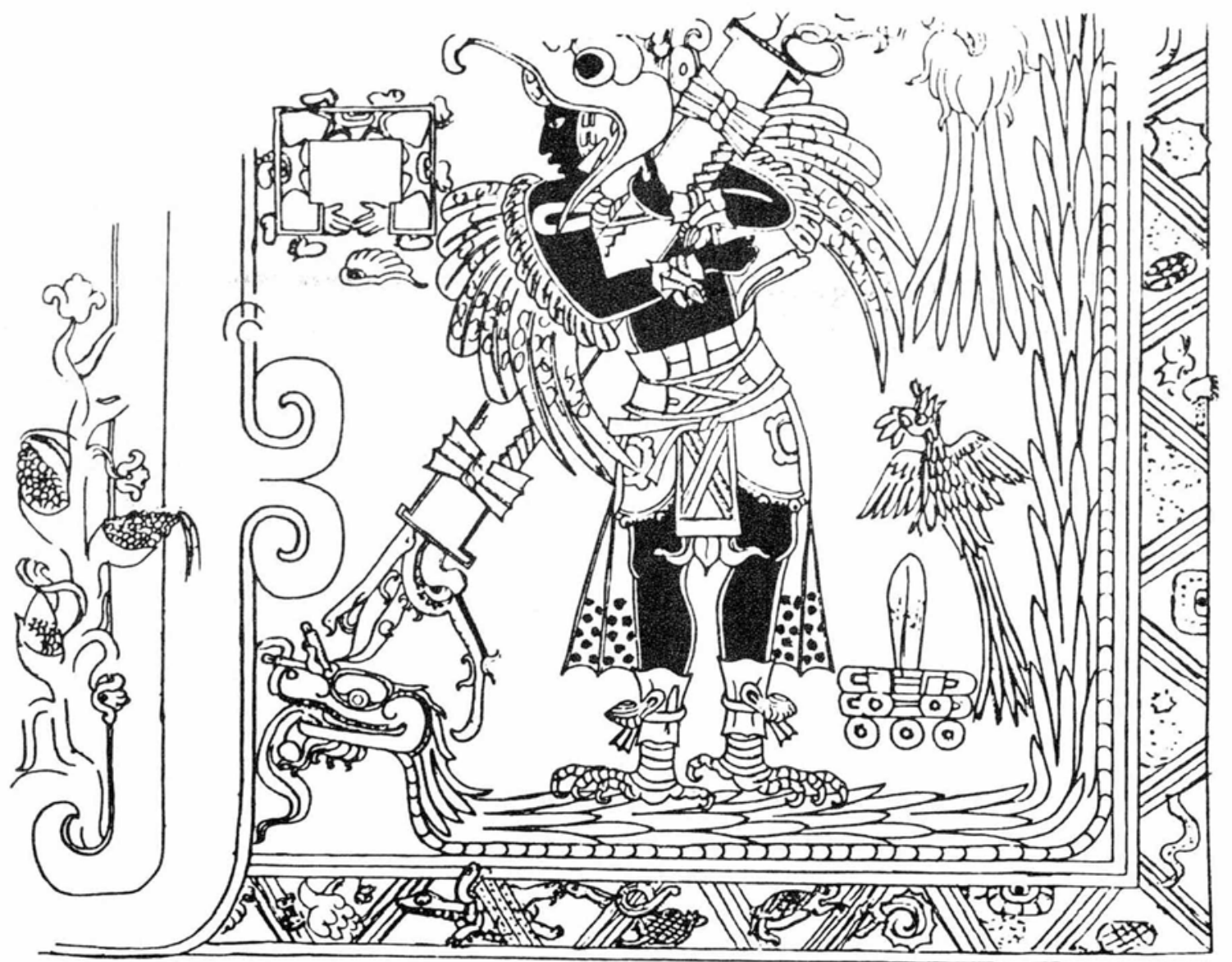

Figura 5. Cacaxtla. Pórtico Edificio A Muro S. E. Hombre Pájaro (según calcas del I.N.A.H.). 
humana, y que en el Pórtico del Edificio A aparecerán subordinados a la imagen del Hombre-Pájaro de facciones mayas (fig. 5).

Para concluir estas breves reflexiones, puedo decir que el acervo artístico de Cacaxtla se enriquece con los datos aquí anotados. El extraordinario desarrollo de la pintura mural en la ciudad durante su periodo de auge tiene estos dos antecedentes que revelan, además de los posibles nexos ya apuntados con Palenque, $y$, por ende, con la tradición míticosagrada de los mayas, la existencia en el sitio de una bien consolidada escuela de pintura.

\section{BIBLIOGRAFIA}

EDMONSON S. MUNRO.

1971 The Book of Counsel the Popol Vuh of the Quiche Maya of Gua. temala. Middle American Research Institute, Pub1. 35. Tulane University, New Orleans.

Foncerrada de Molina, Marta.

1976 "El sacrificio por decapitación en Paleque", en Segunda Mesa Redonda de Palenque (1974). Pre Columbian Art Research Inst. Pebble Beach, California.

1980 "The Cacaxtla Murals an example of Maya cultural contact?" en Iberoamerikanisches Archiv, N.F. 4 (2): 141-160. Berlín.

1982 "The Cacaxtla Murals and Teotihuacan Cosmopolitism," en Third Palenque Round Table (1978) 4 (2): 183-198. University of Texas Press, Austin.

López de Molina, Diana, y Daniel Molina F.

1980 Cacaxtla Guía oficial, INAH, México.

ReCINOS, ADRIÁN.

1947 Popol Vuh: las antiguas historias del Quiché. Fondo de Cultura Económica, México.

Villacoria, I. Antonio y Flavio Rodas.

1927 Manuscrito de Chichicastenango (Popol Buj). Guatemala. 